\title{
Thermal-controlled frictional behaviour of nanopatterned self-assembled monolayers as triboactive surfaces
}

\author{
Philippe Stempfléa)* $^{\text {( }}$ Anne Domatti ${ }^{a)}$, Jamal Takadoum ${ }^{a)}$, Armand Fahs ${ }^{\text {b) }}$, \\ Pascal Carrière ${ }^{\text {b) }}$
}

the date of receipt and acceptance should be inserted later

a) Institut FEMTO-ST (UMR CNRS 6174, Université

Bourgogne - Franche Comté), 15B Avenue des

Montboucons, 25030 Besançon Cedex, FRANCE

b) Université de Toulon, MAPIEM, EA 4323, 83957 La Garde Cedex, FRANCE

Abstract Friction is an important limitation of energy efficiency performances of MEMS/NEMS but is, in the same time, a great opportunity for harvesting energy by designing optimized Tribo-Electric Nano-Generators (TENG). Thus, frictional behaviour can be accurately controlled in real-time by using thermally sensitive periodic patterned self-assembled monolayers of $n$ - octadecyltrichlorosilane (OTS) grafted on MEMS surfaces. Nanopatterns are currently used in order to limit the wear rate without modifying the frictional behaviour. In this work, patterns have been created by micro-contact printing $(\mu \mathrm{CP})$ using a polydimethylsiloxane (PDMS) stamp displaying a trapezoidal profile. Hence pattern periodicity can be continuously changed - and then optimized from discontinuous to pseudo-continuous - by applying a controlled normal load on the soft PDMS stamp. A multiscale tribological study has been carried out on these nano-patterns by using both single-asperity and multi-asperity nanotribometers. Lateral Force Microscopy (LFM) provides the individual frictional behaviour of each pattern's component whereas the multiasperity nanotribometer rather gives the emerging frictional behaviour induced by the patterning according to temperature. As a macroscopic crucial parameter while designing TENG's devices, this macroscopic behavior has to be carefully optimized for each practical applications at the molecular scale. Thus, whereas the microscale frictional behaviour can be precisely optimized by the pattern's periodicity, the macroscopic one can be accurately controlled with values of friction coefficient ranging from 0.12 to 0.04 by varying the contact temperature. In addition, any inertial effects observed in the thermal-controlled frictional behavior of nano-patterns can be drastically reduced using infra-red emission as thermal source.

Address(es) of author(s) should be given

\section{Keywords}

triboactive surfaces;self-assembled monolayers;microcontact printing;thermal-controlled;Triboelectric Nanogenerator (TENG)

Corresponding author: philippe.stempfle@ens2m.fr

\section{Introduction}

The design of materials at the nanoscale is the foundation of many new strategies for energy generation, storage, and harvesting [1]. It is worth mentioning the recent emergence of Tribo-Electric Nano-Generators (TENG) - ie, MEMS devices especially designed for harvesting energy within tribocontacts by combining triboelectrification effects and electrostatic induction, successively [2]. In this framework, the frictional behaviour obviously needs to be accurately controlled and optimized in real time at the asperities scale in order to maximize the recovered energy but, with a design as simple as possible [3]. Similar needs and constraints have also been noticed during the gripping/sliding transition in microrobotics $[4,5,6]$. For instance, stick-slip occurrence and friction control in micro/nanosystems on chips are currently solved by driving many electromechanical actuators using a complex approach that generally involves continuous PID controllers [7] and optimized algorithms [8] even though, it would be simpler to design specific triboactive surfaces instead.

Triboactive surfaces stand for surfaces with controlled frictional behaviour finely tuned in real time by using external stimuli as temperature $[9,10]$, laser beam [11], UV or IR beams [12,13], electric or electrostatic fields [14,15] and many other ways $[16,17]$. For instance, photo- and thermo-activated self-assembled monolayers (SAM) seem to be a promising way for this purpose $[9,10,11,12,13]$ assuming that suitable functional groups can be found or synthesized for each given application. Indeed, selfassembled monolayers have been used for long to both reduce wear $[18,19,20,21,22]$ and friction $[20,21,23,24$, $25,26,27]$ in MEMS but, as far as we know, always as a passive way - ie, without any dynamic external control. The principle of this control mainly consists in influencing the dissipation mechanisms within the contact 
by acting on the reversible order-disorder changes at the molecular scale. As a result, the macroscopic frictional behaviour emerges as a controlled multiscale process $[9$, $28,29]$.

In this work, octadecyltrichlorosilane self-assembled monolayer - so-called OTS SAM - will be used as a model of triboactive surfaces. This SAM reveals an interesting peculiar thermal-controlled frictional behaviour [9] and a good frictional behaviour in MEMS tribological conditions $[18,19,21,22,23,24,25,26,27]$. Unfortunately, it is well known that OTS SAM displays a limited lifespan especially as a continuous monolayer [27] mainly because its entangled molecules $[30,31]$ involve high stresses within the sub-surfaces which, in turn quickly induce substrate seizure [32], especially in case of silicon wafers [27]. To avoid this issue, periodic nano-patterned triboactive surfaces have been designed by grafting OTS SAM using micro-contact printing $(\mu \mathrm{CP})[33,34,35,36,37,38$, $39,40,41]$. This soft lithography technique uses the relief patterns on a PDMS stamp to form nano-patterns of SAMs on the surface of the silicon substrate through conformal contact [39]. This procedure was chosen for several reasons. The main one is that it requires no special equipment to reproduce patterns that can be created by electron-beam lithography [39], replication [34] or inkjet printing [41], for instance. Then, it can be managed industrially using stamping automates without any expensive step of clean room etching [40].

In the following, thermal-activated nano-patterns displaying different pattern's widths (PW) have been printed on smooth silicon wafer. A multiscale tribological study has been carried out on these printed nano-patterns in order to extract: (i) the individual frictional behaviour of each pattern's component at the single-asperity scale and, (ii) the emerging frictional behaviour induced by the patterning according to temperature at the multiasperity scale.

\section{Experimental Part}

\subsection{Samples}

Silicon wafers were ultrasonically cleaned in a detergent (GP $17.40 \mathrm{SUP}$ ), acetone and ethanol for $5 \mathrm{~min}$ before grafting. Then, they were submitted to an oxygen plasma treatment at $100 \mathrm{~W}$ power for $5 \mathrm{~min}$, with a flow rate of oxygen of $50 \mathrm{Lh}^{-1}$ and a processing pressure of $0.4 \mathrm{mbar}$. Such treatment leads to form a thin silicon oxide film on the surface that facilitates SAM deposition on the substrate.

\subsection{Micro-contact printing}

Octadecyltrichlorosilane (OTS - C18) self-assembled monolayers have been grafted using the well-known microcontact printing soft-lithography technique $[33,34,35,36$, $37,38,39,40,41]$ on smooth flat $(100)$ silicon wafers $(n$ type material grown by $\mathrm{CZ}$ process and $p$-doped ; RMS $0.3 \mathrm{~nm}) . \mathrm{CH}_{3}\left(\mathrm{CH}_{2}\right)_{17} \mathrm{SiCl}_{3}$ molecules - provided by Alfa a)

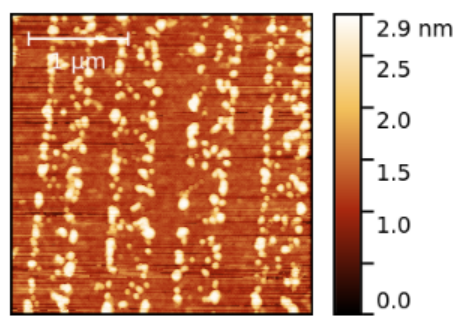

b)

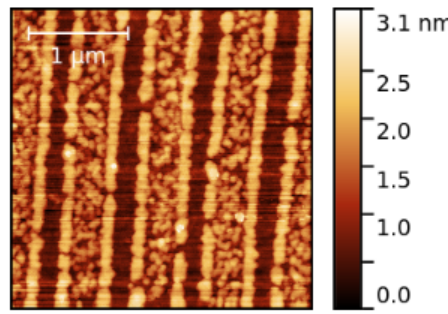

c)

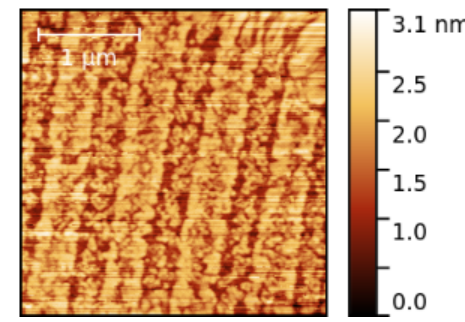

Fig. 1 AFM topographical images of printed nano-patterned monolayers displaying various pattern's width (PW) obtained by applying an increasing normal load on a trapezoidal nano-profiled PDMS stamp: a) $0.1 \mathrm{~N}$ (NP-PW 1); b) $0.15 \mathrm{~N}$ (NP-PW 2); c) 0.2

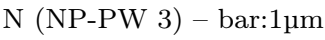

Aesar - were used as delivered. This soft lithography method is based on an elastomeric stamp which is produced by casting poly(dimethylsiloxane) PDMS onto an appropriate bas-relief master [38].

- The master has been extracted from the polycarbonate resin layer of a commercial DVD-R which is an inexpensive standard and reproducible trapezoidal nanostructure - $i e$, top and bottom widths are 420 and 320 $\mathrm{nm}$, respectively. The poly(dimethylsiloxane) stamp is created from the pre-polymer Sylgard 184 (Dow Corning) [42]. The curing agent was mixed with the pre-polymer at a weight ratio of 10:1 [33,35], degassed and poured onto the master. PDMS was subsequently cured at $80^{\circ} \mathrm{C}$ for $2 \mathrm{~h}$. Then, solidified PDMS stamp was finally peeled off from the master, rinsed with ethanol and distilled water in order to remove any released oligomers [35]. As a result, the elastic stamp displays the exact opposite trapezoidal topography of the initial DVD-R structure.

- The elastomeric stamp is then inked with OTS (25 $\mathrm{mM}$ ), and dried with a stream of nitrogen, and finally pressed during 60 s against the smooth silicon surface with a controlled normal load [37]. Molecules are transferred and grafted as a self-assembled monolayer that reproduce the template's pattern of the stamp with a resolution lower than $50 \mathrm{~nm}$ [40]. From the trapezoidal stamp's template the pattern's width $(\mathrm{PW})$ is modified by varying the normal load that is applied on the soft stamp. 


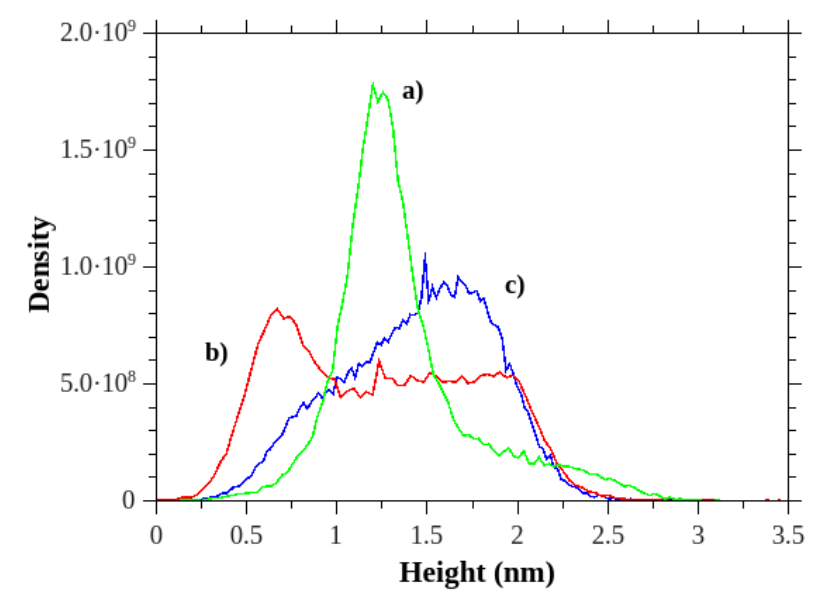

Fig. 2 Typical height distributions of the various printed nanopatterns surfaces carried out using AFM: a) NP-PW 1; b) NP-PW 2 and, c) NP-PW 3

\subsection{Characterization of the printed nano-patterned SAM}

\subsubsection{AFM characterization}

Figure 1 shows a typical view of the three samples that have been created by applying respectively $0.10,0.15$ and $0.20 \mathrm{~N}$ onto the stamp. For the sake of simplicity, these samples will be named respectively NP-PW 1, NP-PW 2 and NP-PW 3 in the following. It is worth noting that the layer's thickness observed by Atomic Force Microscope (AFM) is quite independent of the initial applied load on the stamp (ie, around $3 \mathrm{~nm}$ ). Only the pattern's width (PW) changed from discontinuous (NP-PW 1 and 2) to pseudo-continuous monolayer (NP-PW 3). This observation is quantitatively confirmed by plotting the height distribution of each sample in Fig. 2. None of these height distributions allows us to insure that silicon stripes are free of any grafted OTS molecules. However, single-asperity nanotribological test will be able to check this out with confidence (see. $§ 2.4 .1$ ).

\subsubsection{Infrared Reflection Absorption Spectroscopy}

Infrared reflection absorption spectroscopy (IRRAS) spectra were measured using a Bruker Vertex 70 FT-IR spectrometer equipped with a DTGS detector. As shown in Fig 3, characteristic peaks of asymmetric and symmetric methylene vibration of SAMs $-\nu_{\text {asym }}\left(\mathrm{CH}_{2}\right)$ and $\nu_{\mathrm{sym}}\left(\mathrm{CH}_{2}\right)$ - are well defined in the frequency range of 2750-3050 $\mathrm{cm}^{-1}$ whatever the PW. However, these characteristic peaks - observed at 2920 and $2850 \mathrm{~cm}^{-1}$, respectively - are clearly shifted of about $3 \mathrm{~cm}^{-1}$ with respect to the ones of the initial liquid solution $-i e, v_{\text {asym }}\left(\mathrm{CH}_{2}\right)=2923$ $\mathrm{cm}^{-1}$ and $\nu_{\text {sym }}\left(\mathrm{CH}_{2}\right)=2853 \mathrm{~cm}^{-1}$. According to Bennès et al. [36], this shift can be attributed to a semi-crystalline arrangement of alkyl chains, meaning that the C18 SAM is highly ordered and well grafted on a silicon surface. It is worth noting that this shift has always been observed whatever the PW. Only the peaks' intensity is affected by the amount of organic matter printed on silicon. The latter is obviously too weak to be accurately observed for the lowest PW of the NP-PW 1 sample. Besides, as shown

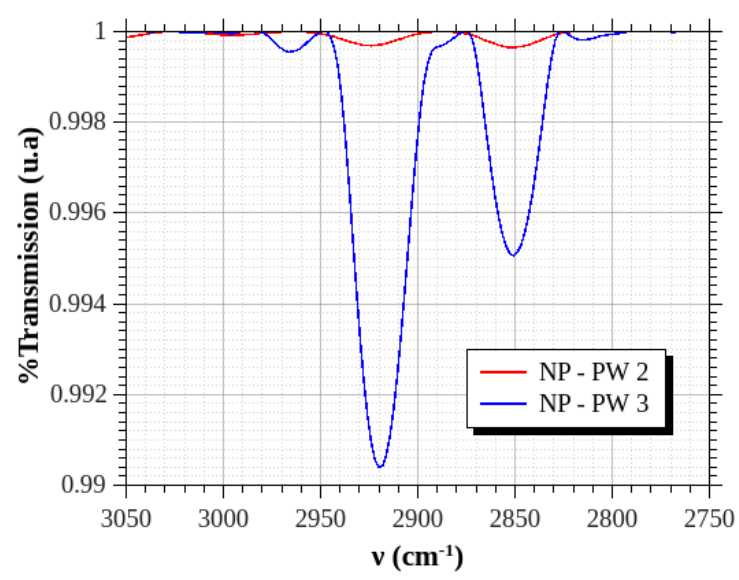

Fig. 3 IRRAS spectra of printed nano-patterned monolayers grafted on polished $\mathrm{Si}(100)$ wafers for different pattern's widths (PW). All spectra were assessed at an incidence angle of $70^{\circ}$. The number of scans was fixed at 16 with a resolution of $4 \mathrm{~cm}^{-1}$.

in Fig. S1, no mass transfer from the PDMS stamp to the silicon wafer has occurred during the stamping process. The complete IRRAS spectrum of all nanopatterns does not display any additionnal peaks in the range 1275-1245 $\mathrm{cm}^{-1}$ corresponding to the $\mathrm{Si}-\mathrm{CH}_{3}$ characteristic peaks [43]. This assumption has been also confimed by wettability measurements reported in table S1. In the following, Kelvin probe analysis will be used in order to remove any doubts about both the grafting process and the presence of possible released oligomers.

\subsubsection{Kelvin probe analysis}

Kelvin probe analysis is a macroscopic non-contact differential method (eg. [44]). It consists to measure the evolution of the surface potential - so-called the Contact Potential Difference (CPD) - before and after the grafting process $-i e$, with respect to the bare silicon reference bias $[44,45,46]$. Surface potential measurements have been carried out using a Kelvin vibrating probe PD $1216 \mathrm{P}(\varnothing 4.6 \mathrm{~mm}$ ) connected to a Trek voltmeter 325 (Trek Inc) at room temperature. The probe surface separation is kept constant for all samples at $0.75 \mathrm{~mm}$ [47]. Thus, positive or negative evolution of the CPD with respect to the reference bias $\left(\mathrm{CPD}_{\mathrm{Si}}=0 \mathrm{~V}\right)$ gives an assessment of the Interfacial Dipole Layer alignment (IDL) within the SAM, which is strongly connected to:

- (i) the thickness [48] and orientation [49] of grafted molecules at the macro- [50] and nanoscale [51]: That means that the CPD continuously increases with the packing density of SAM [52] ;

- (ii) the grafting success [53]: the larger the CPD difference $v s$, the reference bias $\left(\mathrm{CPD}_{\mathrm{Si}}=0 \mathrm{~V}\right)$, the stronger the molecules adhere onto the silicon substrate;

- (iii) the surface reactivity for a given surface [44]: the more negative of the CPD measurement the higher the surface reactivity, according to the reactivity of the reference. In our case, any positive rise of the CPD may be connected to a decrease of the surface reactivity vs. the bare silicon one [45]; 


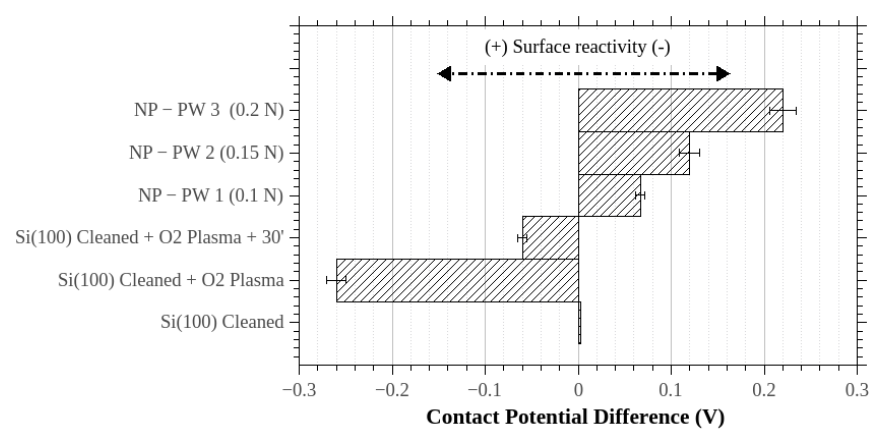

Fig. 4 Surfaces potential of samples assessed by using the Kelvin probe measurements

- (iv) many other tribological properties as friction level or wear precursors detection in the sub-surfaces as reported by several authors $[54,55]$, thus:

Figure 4 compares the CPD of the three printed nanopatterned SAM samples with respect to the bare silicon one taken as the reference with $0 \mathrm{~V}$ bias:

- high positive CPD values for both samples confirm that SAMs are all well grafted on silicon wafer. This technique appears to be even more sensitive than IRRAS for discriminating nano-patterns features on silicon wafers.

- as expected, the more reactive surface - ie, the more negative CPD - is observed just after the oxygen plasma treatment of the silicon wafer. Reactivity continuously decreases with time as shown for plasmatreated bare silicon after $30 \mathrm{~min}$. It is worth noting that the reactivity clearly decreases with the PW which means that friction reduction at the macroscale will probably be expected when PW increases.

These assessments carried out using a macroscopic Kelvin probe involve that pattern's periodicity could be an easy way for statically adjusting frictional behavior of future TENG devices [2] or grippers used in microassembly processes [4].

\subsubsection{Microthermal analysis}

Since our printed nanopatterns have to be controlled by using a thermal stimulus, their thermal behaviour and especially their thermal degradation threshold need to be accurately known. The latter have been both studied using a TA Instruments 2990 Micro-Thermal analyzer [56]. Probe temperature calibration was performed using room temperature and the differential scanning calorimetry (DSC) peak melting point of polyethyleneterephthalate (PET). Using the localized thermal analysis (L-TA) mode of the $\mu \mathrm{TA}$, the probe was held in place at a location selected on the surface, with a force of $12 \mathrm{nA}$ and its temperature was raised from 25 to $350^{\circ} \mathrm{C}$ at a rate of $15^{\circ} \mathrm{C} . \mathrm{s}^{-1}$ and then cooled to $25^{\circ} \mathrm{C}$. The vertical position of the probe during heating was followed by laser displacements focus on the probe (so-called, pTMA, localised thermomechanical analysis, or sensor signal). Figure 5 shows the result of the micro-thermal analysis carried out on the NP-PW 3 sample. The decreasing curve corresponds to the thermal power injected within the sample

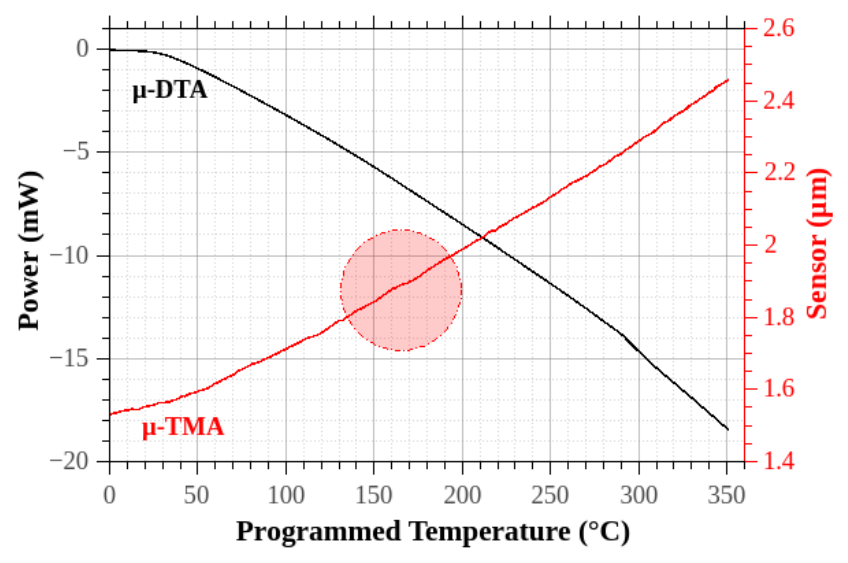

Fig. 5 Typical $\mu$ DTA and $\mu$ TMA analysis carried out on the NP PW3 sample. Thermal degradation begins at $160^{\circ} \mathrm{C}$ corresponding to an injected thermal power of about $7 \mathrm{~mW}$

( $\mu$ DTA plot). The increasing curve corresponds to the thermal expansion of the sample ( $\mu$ TMA plot). These plots reveal that the degradation of the monolayer only starts when the temperature reaches $160^{\circ} \mathrm{C}$ (dashed circle) which corresponds to an injected thermal power of 7 $\mathrm{mW}$. This micro-thermal behaviour is in agreement with the thermal desorption ones published elsewhere $[57,58$, 59].

\subsection{Tribological setup}

As an emergent phenomenon is expected vs the pattern's width, tribological test will be carried out at both the single-asperity and the multi-asperity scale by using two different devices:

\subsubsection{Single-asperity nanotribology}

An AFM Multimode 8 from Bruker has been used in friction mode as a single-asperity nanotribometer at ambient temperature $[27,60,61]$. The silicon nitride probe displays a round tip of $20 \mathrm{~nm}$. Its work frequency is 23 $\mathrm{kHz}$. The cantilever's stiffness is evaluated at $0.14 \mathrm{~N} / \mathrm{m}$ using thermal calibration method [62]. The normal applied load of $1 \mathrm{~V}$ corresponds to $6.9 \mathrm{nN}$, and the sensitivity of the probe has been determined on sapphire surface $(49.2 \mathrm{~nm} / \mathrm{V})$ [62]. The scanning rate is $6 \mu \mathrm{m} / \mathrm{s}$. Friction measurements have been performed at different applied loads $\mathrm{F}_{\mathrm{n}}$ varying from 1.5 to $42 \mathrm{nN}$ in air and at room temperature by changing the applied voltage from 1 to $6 \mathrm{~V}[63]$.

Figure 6 shows the procedure that has been carried out to study (i) the influence of the PW and (ii) the contribution of each pattern's component - ie, the silicon and OTS stripes, respectively - on the single-asperity frictional behaviour. Thus,

- a Trace-Retrace couple of maps (Fig. 6a and b) have been plotted for each applied loads $\left(F_{n}\right)$ in order to ascertain that none artifact may be ascribed to sample's topography in friction results;

- from these maps, lateral force profiles (Fig. 6b) have been extracted - by using the SPM software Gwyd- 
a)

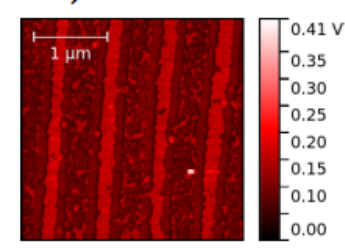

Trace
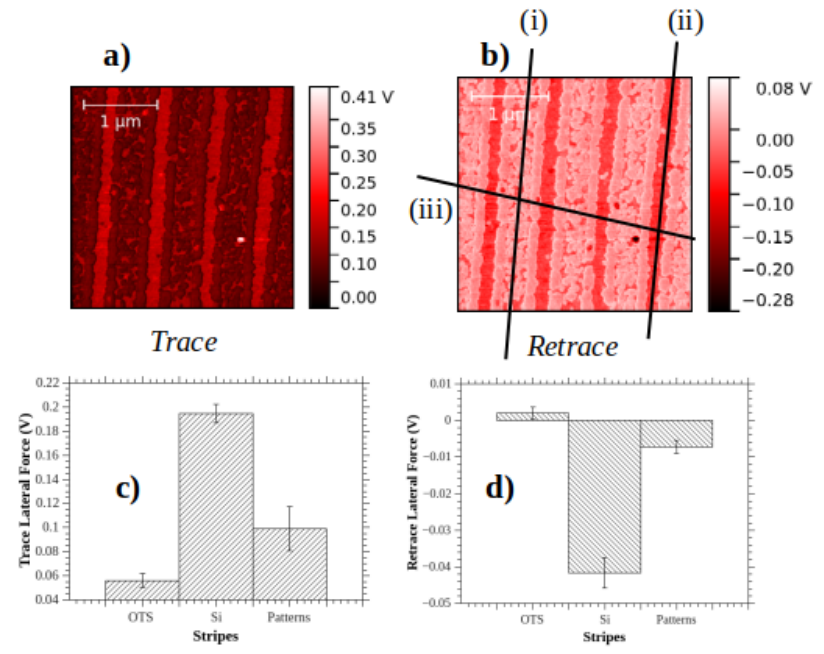

Fig. 6 Single-asperity nanotribological procedure, applied for instance on NP-PW 2 sample with $\mathrm{F}_{\mathrm{n}}: 1.38 \mathrm{nN}(0.2 \mathrm{~V})$. Trace (a) and Retrace (b) map ; Trace (c) and Retrace (d) lateral force computed from various lateral force profile carried out on (i) $144 \mathrm{~nm}$ wide OTS stripe ; (ii) $144 \mathrm{~nm}$ wide Silicon stripe and (iii) $1.5 \mu \mathrm{m}$ wide Pattern stripe

dion (http://gwyddion.net/) - on each stripes in order to get the frictional contribution of: the pure OTS stripe (i), the bare silicon stripe (ii); and the whole pattern displaying various PW (iii). Profile's widths are actually 12 pixels - ie, $144 \mathrm{~nm}$ wide - for the profiles (i) and (ii) and 128 pixels - ie, $1.5 \mu \mathrm{m}$ wide - for the profile (iii) for the sake of statistical validity;

- from these profiles, average and standard deviation of lateral force have then been computed as shown in Fig. $6 \mathrm{c}$ and d;

For instance, these values have been plotted respectively for the Trace (Fig. 6c) and Retrace maps (Fig. 6d) carried out for the NP-PW 2 sample at $F_{n}=1.38 \mathrm{nN}$. Results show that the frictional contribution of this surface has two boundaries that are delimited, on the one hand, by the silicon contribution (the highest lateral force), and on the other hand, the OTS contribution (the lowest lateral force). The actual patterns display of course tribological behaviours that are in-between these boundaries but, as mentioned above, this behaviour is likely to be adjusted within these boundaries by simply varying the PW of the sample.

Since it is well known that a loading dependence of the frictional force is likely to be observed for a singleasperity contact under weak normal loads [64], previous results have been studied by considering the combination of the Bowden-Tabor's adhesion model $\left(i e, F_{t} \propto A_{r}\right)$ and the Hertzian contact mechanics $\left(i e, A_{r} \propto F_{n}^{\frac{2}{3}}\right) . A_{r}$ is here the real contact area between the asperity (AFM probe) and the sample for a given normal load $F_{n}$. This model is generally formulated as [64]:

$F_{t}=\mu_{0}\left(F_{n}+F_{A d h}\right)^{\frac{2}{3}}$

with

$\mu_{0}=\tau \pi\left(\frac{R}{E^{\prime}}\right)^{\frac{2}{3}}$
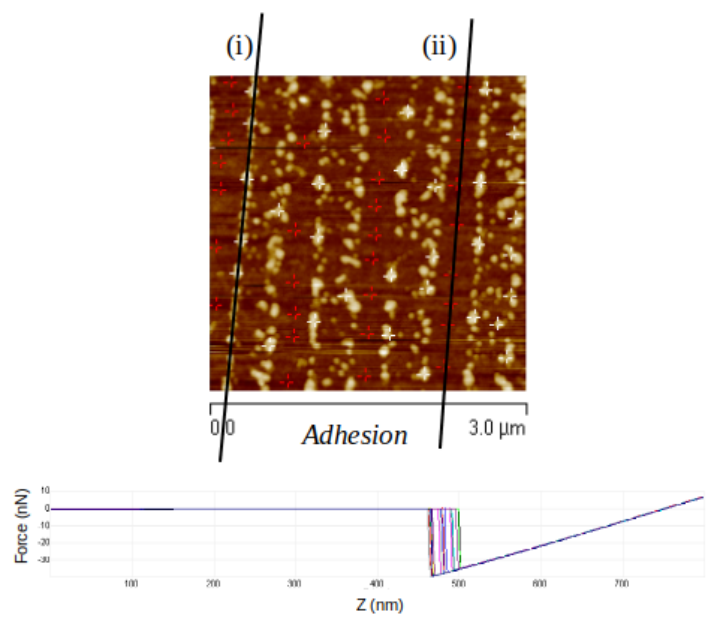

Fig. 7 Typical single-asperity pull-off test leading to the extraction of the adhesion force $\left(\mathrm{F}_{\mathrm{Adh}}\right)$ of each stripe. The force-distance curves are carried out on (i) OTS stripe and (ii) silicon stripe of NP-PW 1, for instance

where, $\mu_{0}$ is homogeneous to the friction coefficient; $\tau$, the shear stress; $R$, the tip radius, and $E$ ' the equivalent Young's modulus combining the Poisson's ratios and Youngs' modulii of probing tip and sample:

$\frac{1}{E^{\prime}}=\frac{1-\nu_{\text {tip }}^{2}}{E_{\text {tip }}}+\frac{1-\nu_{\text {sample }}^{2}}{E_{\text {sample }}}$

Assuming a constant shear stress $\tau$, only $\mu_{0}$ will be extracted by fitting the model (1) on the experimental plots, as shown for instance in Fig 8 for the silicon stripes. In the relationship (1), $F_{\text {Adh }}$ is the average pull-off force measured experimentally on each pattern's component from force-distance curves obtained for all NP-PW samples $-i e$, by disabling the lateral movement but allowing normal movement only [65]. The procedure is illustrated in Fig 7 for NP-PW 1: each red and white cross corresponds to an assessment location on silicon stripes and OTS stripes, respectively. $F_{A d h}$ is then calculated for each stripe by averaging all discrete pull-off forces measured along their respective stripes. Hence, $F_{\text {Adh }}$ obtained on profile (i) and (ii) in Fig 7 can reasonably be connected to the frictional results obtained for the same profiles in Fig 6b.

To definitively check the quality of the surface patterning process, the loading dependence of the frictional force is studied for tribological tests carried out on the silicon stripes only. Thus, the model (1) is fitted on experimental points for profiles (ii) in Fig. 6 - for samples NP-PW 1 and PW 2, respectively, in order to find $\mu_{0}$ for each silicon stripe. Results are then compared to the one carried out on a bare silicon wafer as reference. All these values are compiled in Table 1 with the measured $F_{A d h}$ and the corresponding correlation coefficient $\mathrm{R}^{2}$.

They reveal that $\mu_{0}$ of all silicon stripes are very close to the bare silicon one. This means that the patterning process - and so, the stamping one - worked quite well since there is obviously no OTS molecules within the silicon stripes. These frictional results are clearly more quantitatively convincing than the previous topographical results showed in Fig. 2 in order to prove that the expected patterning surface is well-done. To strengthen 


\begin{tabular}{cccc}
\hline & $\mu_{0}$ & $F_{\text {Adh }}$ & $\mathrm{R}^{2}$ \\
\hline Bare Si(100) & 0.066 & $-1.74 \mathrm{~V}(-12 \mathrm{nN})$ & 0.89 \\
Si Stripes of NP-PW 1 & 0.063 & $-3.45 \mathrm{~V}(-23 \mathrm{nN})$ & 0.97 \\
Si Stripes of NP-PW 2 & 0.057 & $-2.84 \mathrm{~V}(-20 \mathrm{nN})$ & 0.94 \\
\hline
\end{tabular}

Table 1 Fitted $\mu_{0}$ of the loading dependence frictional relationship for silicon stripes. $F_{A d h}$ is an averaged value from all discrete experimental pull-off forces assessed along their respective stripes.

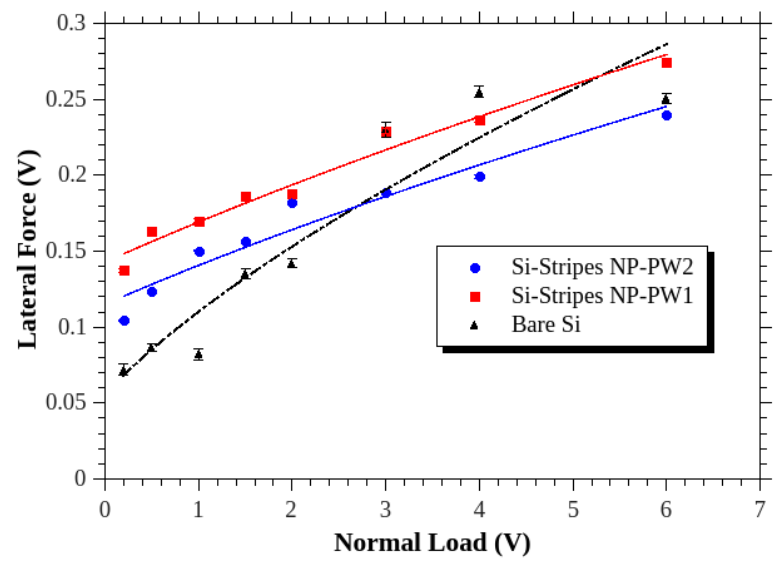

Fig. 8 Loading dependence of the frictional behaviour carried out at the nanoscale on the silicon stripes of each sample. The dashed curve is the bare silicon wafer as reference. Fitted parameters are reported in Table 1

this assumption, the OTS stripes display the same $\mu_{0}$ as the continuous OTS self-assembled monolayer - ie. 0.028 $\pm 5.10^{-4}$. These results confirm the relevance of the $\mu_{0}$ extraction method used at the local scale, and the quality of the surface patterning.

\subsubsection{Multi-asperity nanotribology}

A ball-on-disc multi-asperity Nanotribometer CSM Instruments (Switzerland) [66] in reciprocating mode has been equipped with a Peltier module in order to control the sample's temperature from 10 to $95^{\circ} \mathrm{C}-i e, \Delta \mathrm{T}$ $=85^{\circ} \mathrm{C}[9]$. As mentioned in $\S 2.3 .4$ and in Fig. 5, this range of temperature should not involve thermal damage within the OTS SAMs. A rough silicon nitride ball ( $\varnothing 4$ $\mathrm{mm}$ ) is put in contact against a flat (100) silicon wafer covered by the nano-patterned SAMs. Normal loads applied on the ball are $10 \mathrm{mN}$ and $70 \mathrm{mN}$ which correspond to a contact pressure of 150 and $270 \mathrm{MPa}$, respectively. Sliding velocity and sliding amplitude are $1 \mathrm{~mm} . \mathrm{s}^{-1}$, and $\pm 0.5 \mathrm{~mm}$, respectively.

\section{Results and discussion}

3.1 Influence of the PW on the single-asperity nanotribology at a constant normal load

Figure 9 shows the distribution of the lateral force measured at a constant normal load of $27.6 \mathrm{nN}-i e 4 \mathrm{~V}-$ for all nano-patterned samples with respect to the bare silicon wafer, as reference. This distribution corresponds to the samples in which the height distribution was plotted in Fig. 2. In contrast to the latter, two populations can be here accurately discriminated for the frictional

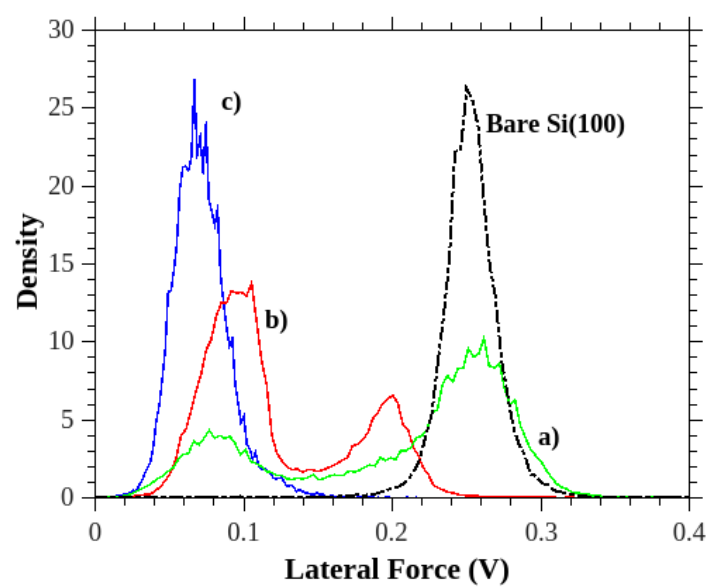

Fig. 9 Typical single-asperity frictional behaviour carried out at constant normal load $(27.6 \mathrm{nN}-4 \mathrm{~V})$ of printed nanopatterned monolayers displaying different PW: a) NP-PW 1; and b) NP-PW 2 ; and c) NP-PW 3. The dashed curve is the bare silicon wafer as reference. The corresponding height distributions are plotted in Fig. 2

\begin{tabular}{cccc}
\hline & $\mu_{0}$ & $F_{\text {Adh }}$ & $\mathrm{R}^{2}$ \\
\hline Bare Si(100) & 0.066 & $-1.74 \mathrm{~V}(-12 \mathrm{nN})$ & 0.89 \\
Patterns NP-PW 1 & 0.049 & $-4.26 \mathrm{~V}(-29 \mathrm{nN})$ & 0.95 \\
Patterns NP-PW 2 & 0.034 & $-3.61 \mathrm{~V}(-25 \mathrm{nN})$ & 0.84 \\
Patterns NP-PW 3 & 0.022 & $-2.21 \mathrm{~V}(-15 \mathrm{nN})$ & 0.97 \\
\hline
\end{tabular}

Table 2 Fitted $\mu_{0}$ of the loading dependence frictional relationship for pattern stripes. $F_{A d h}$ is an averaged value from discrete experimental pull-off forces.

behaviour (Fig. 9). The lowest and the highest peak of each distribution correspond respectively to OTS and to silicon frictional contribution. Thus, the discontinuous NP-PW 1 (Fig. 9a) reveals a silicon contribution which is twice the OTS one. Unlike the pseudo-continuous NPPW 3 sample (Fig. 9c) tends to have an homogeneous frictional behaviour which is very close to the pure OTS one. Thus, at the single-asperity scale, nanopatterns' frictional behaviour can be accurately adjusted by the PW as shown in Fig 9b for the NP-PW2. But does this behaviour occurring at the nanoscale still affect the frictional behaviour at the macroscale?

By considering that a multi-asperity real contact area is always larger than the PW dimensions, and that the boundary conditions in friction are always given by the OTS and the silicon in the absence of any SAM damages, then the emerging frictional behaviour is likely to come from the averaging of the original bimodal distributions, themselves controlled by the PW, as shown in Fig. 9b.

As a result, PW will probably still have an influence at the macroscopic scale by controlling the weighted averaging process within the multi-asperity real contact area. Before checking this assumption out in $\S 3.3$, let us observe the influence of the normal load on the singleasperity frictional behaviour.

3.2 Influence of the PW on the loading dependence of single-asperity friction

Figure 10 plots the evolution of the lateral force $v s$. normal load for all the nano-patterned surfaces. As previ- 
ously mentioned these results are extracted from frictional profiles (iii) showed in Fig 6b. Bare silicon behaviour is plotted as a reference. Experimental scatter plots are fitted using the relationship (1) in order to extract the frictional coefficient $\mu_{0}$ by considering the experimental $F_{\text {Adh }}$ both compiled in Table 2.

On the one hand, in Table 2, the average value of $\mu_{0}$ clearly decreases with the PW in good correlation with the results obtained with the Kelvin probe (Fig. 4) meaning that the friction coefficient is likely to be connected with the surface reactivity of the patterns and so, to the physico-chemical component of the friction. Indeed Trace-Retrace plots confirm that the topography has a negligible influence on the lateral force. Note that the correlation coefficient of the NP-PW 2 is worse than the ones of other samples. This is probably because the assumption concerning the constant shear stress $\tau$ is no longer valid when the width of each pattern's component is quite close. In this case, shear stress should have too different values $\left(\tau_{S i}\right.$ and $\left.\tau_{O T S}\right)$ only licit on their respective domain.

On the other hand, evolution of the lateral force against the normal load reported in Fig. 10 gives some information related to the presence of any pattern-width-induced critical contact pressure, which is connected to a normal load threshold that the nano-patterns is unable to bear for maintaining a low frictional regime. However, this critical contact pressure seems to depend on the patternwidth, indeed:

- when the pattern-width is high enough - ie, for NPPW 2 and 3 where the red and blue curves always stay below the dashed black curve whatever the applied normal load (Fig. 10) - there is no critical contact pressure induced by the pattern-width ; bare silicon frictional behaviour always stays the highest one whatever the normal load applied ;

- in contrast, the intersection between the green and the dashed black curves reveals that NP-PW 1 displays a critical contact pressure at $300 \mathrm{MPa}$ pointed by the black arrow. This value has been computed by considering the contact area under the AFM tip of $20 \mathrm{~nm}$ loaded by a normal load of $17 \mathrm{nN}$ (ie, at 2.5 $\mathrm{V}$ in Fig. 10) in presence of an adhesion force [65]. Thus in Fig. 10, the lateral force assessed for NP-PW 1 below this contact pressure threshold $-c f$. black arrow - is always greater than the one measured for the bare silicon in the same contact conditions. NP-PW 1 nano-patterns are then unable to hold the applied normal load in this range of contact pressure. This behaviour could be attributed to some topographical effects induced by the distant molecules grafted on bare silicon, and so, by the ratio between the size of the AFM tip and the pattern-width. Above this critical contact pressure, NP-PW 1 progressively develops a load bearing capacity, which is sufficient to continuously decreases the lateral force with respect to the bare silicon, while the normal load increases. Hence, this critical contact pressure could be the key parameter for setting the minimum value of the pattern width.

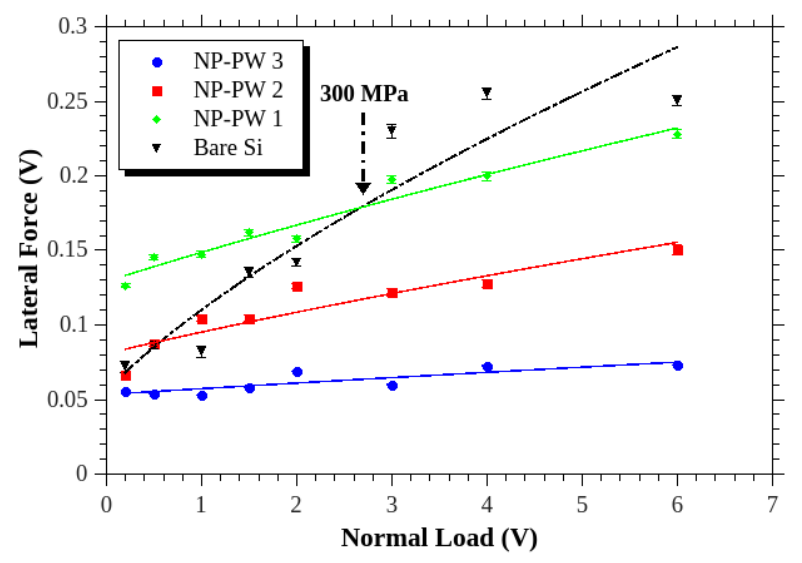

Fig. 10 Loading dependence of the frictional behaviour carried out at the nanoscale on the printed nano-patterned monolayers stripes of each sample. The dashed curve is the bare silicon wafer as reference. Fitted parameters are reported in Table 2

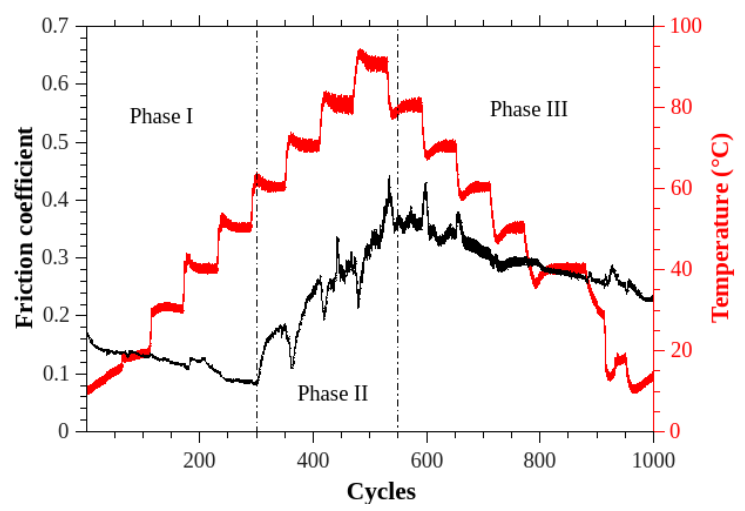

Fig. 11 Evolution of the friction coefficient vs. temperature for the NP-PW 1 sample (Ball: $\mathrm{Si}_{3} \mathrm{~N}_{4} \varnothing 4 \mathrm{~mm}-\mathrm{v}: 1 \mathrm{~mm} \cdot \mathrm{s}^{-1}-\mathrm{d}: \pm$ $\left.0.5 \mathrm{~mm}-\mathrm{F}_{\mathrm{n}}: 10 \mathrm{mN}-\mathrm{p}_{\mathrm{c}}: 150 \mathrm{MPa}\right)$. Plots are smoothed with a 100 points adjacent averaging algorithm

The point here is that the level of the critical contact pressure noticed for NP-PW1 $(\approx 300 \mathrm{MPa})$ is clearly in the range of the actual contact pressure, which is applied in multi-asperity nanotribological tests, where the

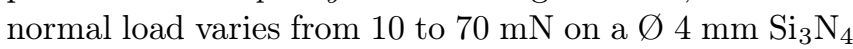
ball (§3.3). This means that the intrinsic lack of bearing capacity of NP-PW 1 at low contact pressure - noticed at the single-asperity scale - will be likely to be observed at the multi-asperity scale - and probably at the macroscale too - because increasing scale always leads to decrease the contact pressure. On the contrary, no such behaviour should be expected at the macroscale for NPPW 2 and 3 samples. This assumption will be checked in the following.

3.3 Influence of the PW on the thermal-controlled frictional behaviour at the macroscale

\subsubsection{Sample NP-PW 1}

Figure 11 plots the evolution of the friction coefficient versus the temperature and the number of cycles of the NP-PW 1 sample under a normal load of $10 \mathrm{mN}$ (smoothed with a 100 points adjacent averaging algorithm). The stimulus range, $i$ n-between $15^{\circ} \mathrm{C}$ and $90^{\circ} \mathrm{C}$, is not able 


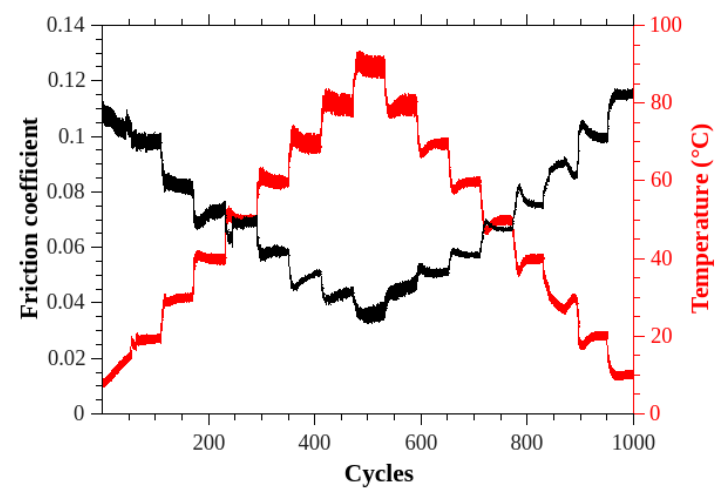

Fig. 12 Evolution of the friction coefficient vs. temperature for the NP-PW 3 sample (Ball: $\mathrm{Si}_{3} \mathrm{~N}_{4} \varnothing 4 \mathrm{~mm}-\mathrm{v}: 1 \mathrm{~mm} \cdot \mathrm{s}^{-1}-\mathrm{d}: \pm$ $\left.0.5 \mathrm{~mm}-\mathrm{F}_{\mathrm{n}}: 10 \mathrm{mN}-\mathrm{p}_{\mathrm{c}}: 150 \mathrm{MPa}\right)$. Plots are smoothed with a 100 points adjacent averaging algorithm

to damage the nano-patterned surfaces as demonstrated in Fig. 5. Thus:

- increasing temperature from 15 to $60^{\circ} \mathrm{C}$ (Phase I, Fig. 11) first leads to decrease the friction coefficient by a factor 2. This interesting thermal-control of the frictional behaviour can be explained by reminding that the gauche factor of OTS - ie, the fraction of the number of gauche defects over the total number of torsion angles in molecular chains - is known to grow with temperature [23] leading, in turn, to decrease the monolayer's stiffness [9]. This behaviour is thermally reversible because it mainly involves modifications of the van der Waals interchain attraction [24].

- however, friction coefficient rises abruptly in phase II to finally stay locked at a value which is very close to the silicon one, while temperature has kept increasing. It is worth noting that the smooth $\mathrm{Si}(100)$ generally displays a friction coefficient which is likely to vary strongly vs. crystallographic directions within the (100) plan - typically in-between 0.20 and 0.38 $[32,66]$. Then, this value decreases very slightly (phase III) while the temperature is returning to its initial value. During the last two phases, thermal-control of the frictional behaviour is no longer allowed because the latter is completely controlled by the silicon component (stripes) of the NP-PW 1.

This behaviour can be explained by noticing that the contact pressure $(i e, 150 \mathrm{MPa})$ is here below to the critical contact pressure threshold of NP-PW $1(\approx 300 \mathrm{MPa}$ in Fig. 10) where its frictional level is higher than the bare silicon one. Besides, the actual contact pressure is also controlled by temperature since rising temperature leads to reduce the SAM's stiffness $[9,23,24]$. As a result, NPPW 1 is no longer able to develop a sufficient load bearing capacity vs. temperature; its tribological behaviour becomes progressively controlled by the silicon substrate instead, which itself has not a thermal-induced frictional behaviour.

\subsubsection{Sample NP-PW 3}

Figure 12 shows the thermal-controlled frictional behaviour of the NP-PW 3 sample under the same conditions $\left(F_{n}\right.$ :

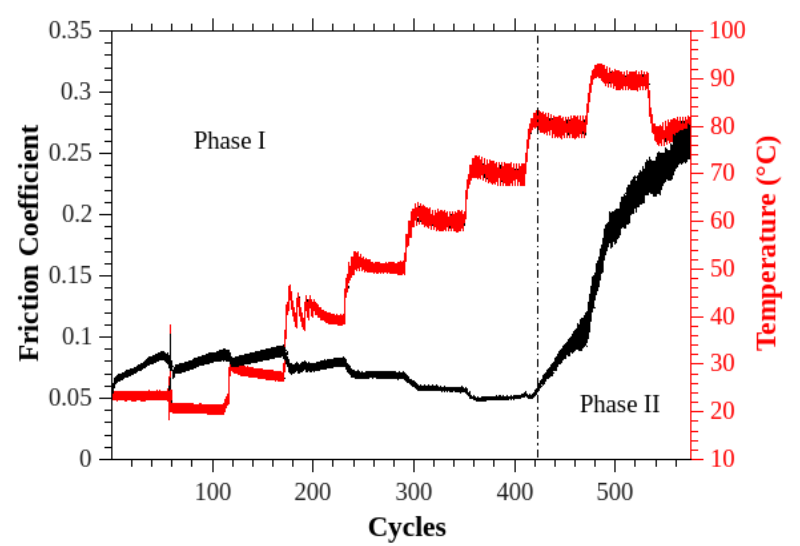

Fig. 13 Evolution of the friction coefficient vs. temperature for the NP-PW 3 sample (Ball: $\mathrm{Si}_{3} \mathrm{~N}_{4} \varnothing 4 \mathrm{~mm}-\mathrm{v}: 1 \mathrm{~mm} \cdot \mathrm{s}^{-1}-\mathrm{d}: \pm$ $\left.0.5 \mathrm{~mm}-\mathrm{F}_{\mathrm{n}}: 70 \mathrm{mN}-\mathrm{p}_{\mathrm{c}}: 270 \mathrm{MPa}\right)$. Plots are smoothed with a 100 points adjacent averaging algorithm

$10 \mathrm{mN}-150 \mathrm{MPa}$ ). Since this sample does not have any peculiar pattern-width-induced critical contact pressure, its frictional behaviour can be perfectly controlled with the temperature. Control is both reactive and reversible up to 1000 cycles, as expected.

Unfortunately, by increasing the normal load to 70 $\mathrm{mN}$ (ie, $270 \mathrm{MPa}$, Fig. 13) the thermal-controlled frictional behaviour vanishes when temperature reaches $70^{\circ} \mathrm{C}$ in the same way as the above NP-PW 1. The main difference here is that the rise of the friction coefficient induces damaging of the silicon substrate in contrast to what we have observed above for NP-PW 1. Indeed, substrate seizure is here clearly observed after 1000 cycles of sliding [67]. This kind of wear behaviour was already observed on continuous OTS SAM grafted by immersion where entangled molecules induce high stresses in the sub-surface leading to seizure of the silicon substrate $[9$, 27].

An important point is that the lost of the thermalcontrolled frictional behaviour is here clearly connected with an irreversible wear process of the substrate. The latter has been explained in [67] and will be published elsewhere. This behaviour is completely different from the one observed for the NP-PW 1 where silicon substrate did not suffer any wear during the thermal-controlled tribological test. What happens for a nanopatterned surface displaying an intermediate pattern's width?

\subsubsection{Sample NP-PW 2}

Figure 14 shows the thermal-controlled frictional behaviour of the NP-PW 2 sample under a pretty high pressure conditions: $\mathrm{F}_{\mathrm{n}}$ : $70 \mathrm{mN}-270 \mathrm{MPa}$. Friction coefficient is here perfectly controlled by the temperature as a sensitive and reversible process up to 1000 cycles. More interesting is its thermal-controlled frictional behaviour tested on over 1000 cycles as plotted in Fig. 15. Frictional control is here completely reversible on a large number of cycles with a slight hysteresis. There is no lost of frictional control and no damaging with respect to the temperature for this PW value. In addition, it has been observed in [67] that the lifespan of this kind of nanopatterns is increased by a factor of about twenty with respect to the 


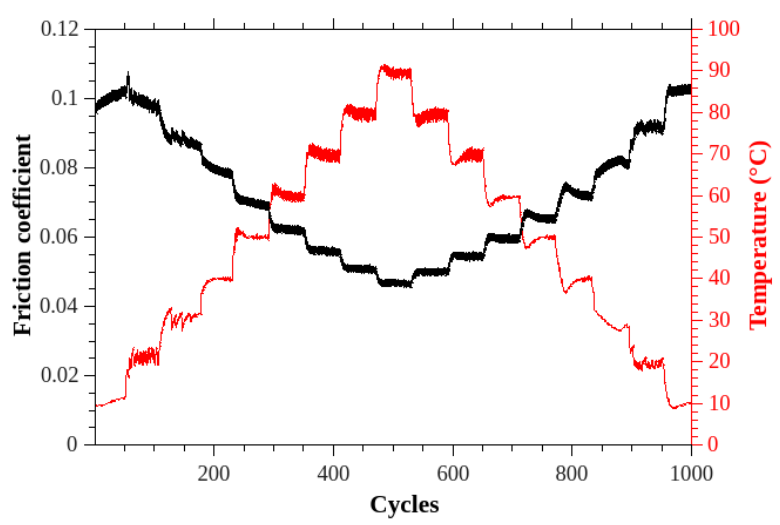

Fig. 14 Evolution of the friction coefficient vs. temperature for the NP-PW 2 sample (Ball: $\mathrm{Si}_{3} \mathrm{~N}_{4} \varnothing 4 \mathrm{~mm}-\mathrm{v}: 1 \mathrm{~mm} \cdot \mathrm{s}^{-1}-\mathrm{d}: \pm$ $0.5 \mathrm{~mm}-\mathrm{F}_{\mathrm{n}}: 70 \mathrm{mN}-\mathrm{p}_{\mathrm{c}}: 270 \mathrm{MPa}$ ). Plots are smoothed with a 100 points adjacent averaging algorithm

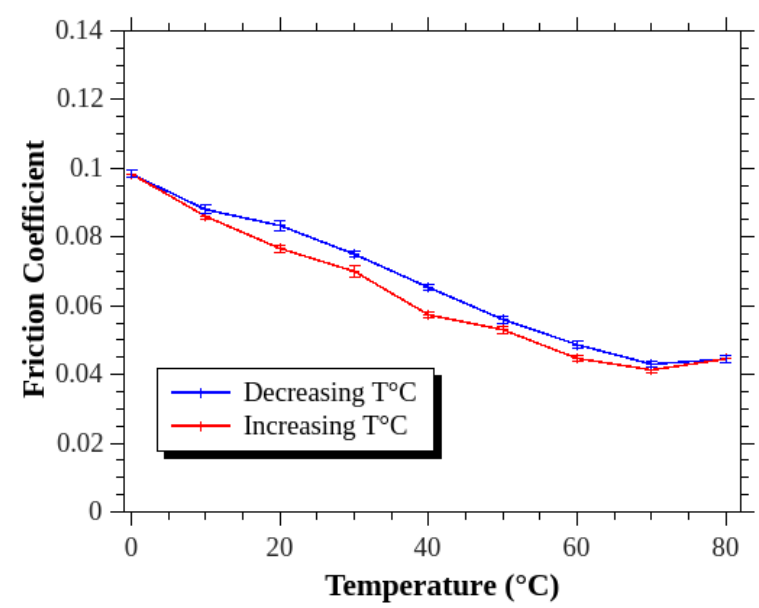

Fig. 15 Reversible frictional control of the NP-PW 2 sample using temperature (Ball: $\mathrm{Si}_{3} \mathrm{~N}_{4} \varnothing 4 \mathrm{~mm}-\mathrm{v}: 1 \mathrm{~mm} \cdot \mathrm{s}^{-1}-\mathrm{d}: \pm 0.5 \mathrm{~mm}-$ $\mathrm{F}_{\mathrm{n}}: 70 \mathrm{mN}-\mathrm{p}_{\mathrm{c}}: 270 \mathrm{MPa}-5000$ cycles). Each point corresponds to the stabilized friction coefficient averaged on 5000 cycles

NP-PW 3. Indeed, the presence of a suitable patternwidth naturally reduces the shear stresses within the silicon substrate which, in turn, push the seizure theshold away [67].

\subsection{IR-controlled frictional behaviour of NP-PW 2}

In the above results, it is worth noting that inertial effects are likely to slow down the thermal control on the frictional behavior. This delay can be problematic for controlling frictional instabilities as stick-slip phenomena observed in microgripping, for instance $[4,5,6,7]$. To check this assumption out, an Infra-Red LED OSLON Black series SFH 4725S, Ø2.76 mm, $\lambda: 940 \mathrm{~nm}, 935 \mathrm{~mW}$ [68] has been mounted instead of the silicon nitride ball on the nanotribometer. This LED is fixed on an air-cooled support equipped with 4 radiators (Intelligent LED Solutions, ILH-IO01-94SL-SC201-WIR 200). Thus, the IRLED is both (i) a "clear" silicone spherical counterface in contact with nanopatterns and, (ii) the heater device in which the thermal flow can be focused at the contact area owing a viewing angle of $80^{\circ}$. Tribological test has been carried out at room temperature and the IR-LED is alternatively set-on or off manually. During the on

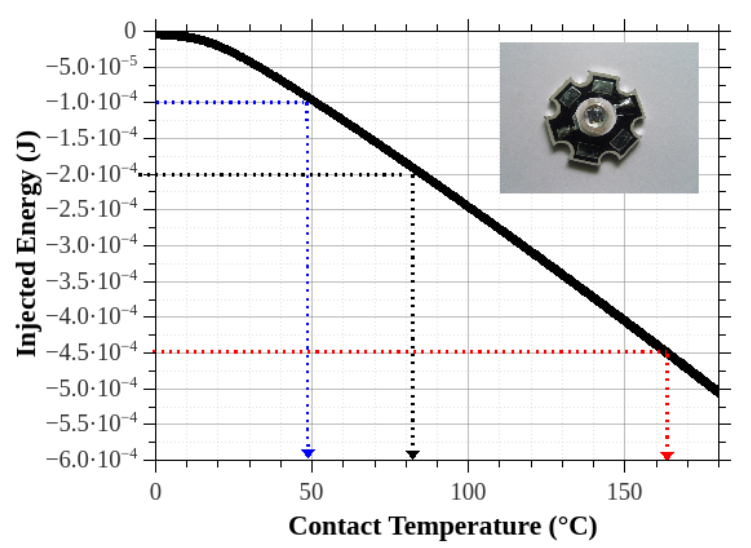

Fig. 16 Relationship between the energy injected in the contact by the IR-LED and the contact temperature of the OTS monolayer. Red arrow shows the ultimate injected energy leading to the OTS SAM degradation. The maximum test duration in on-mode is evaluated at $45 \mathrm{~s}$ or 22 cycles. Blue and Black curves refer to the tests plotted in Fig. 17. Inset: The IR-LED mounted on its air-cooled support

mode, the IR-LED is however electronically driven using pulse-width modulation in order to control how much power is really injected by the LED within the contact area. In this on mode the real injected thermal power is in fact averaged on the whole cycles from 0 to $100 \%$ by sending out a series of pulses - ie, around 500 times per second - controlled by a suitable duty-cycle. The latter is then chosen for limiting self-heating of the LED during the on modes which itself could lead to thermal degradation of the OTS nano-patterns. Thus, the average thermal power really injected within the contact can be accurately controlled by the duty-cycle.

\subsubsection{Ultimate thermal energy injected in the contact area}

The average thermal power really injected within the contact is limited by the maximum contact temperature that the OTS SAM can hold before degradation. This maximum thermal power has been assessed in $\mu$-DTA curve plotted in Fig. 5 for a contact temperature around $160^{\circ} \mathrm{C}$, that is $7 \mathrm{~mW}$. Considering the heating rate of $15^{\circ} \mathrm{C} / \mathrm{s}$, Fig. 16 plots the same evolution but for the thermal injected energy vs. contact temperature. Thus, the maximum thermal energy which leads to the nanopatterns degradation can be estimated at $4.5 \cdot 10^{-4} \mathrm{~J}$ (red arrow). This ultimate value must not be reached during the tribological test otherwise nanopatterns can be damaged. This can be carried out by controlling (i) the amount of thermal power injected by the LED within the contact area (ie, the duty-cycle) and (ii) the duration of the tribological test in the on-mode.

\subsubsection{Amount of thermal energy injected by the IR-LED within the contact area}

The thermal power injected by the IR-LED within the contact area can be evaluated by considering that the LED can provides $850 \mathrm{~mW}$ per steradian [68]. The solid angle involved in our tribological test is easily estimated by considering that the only contribution of the thermal 


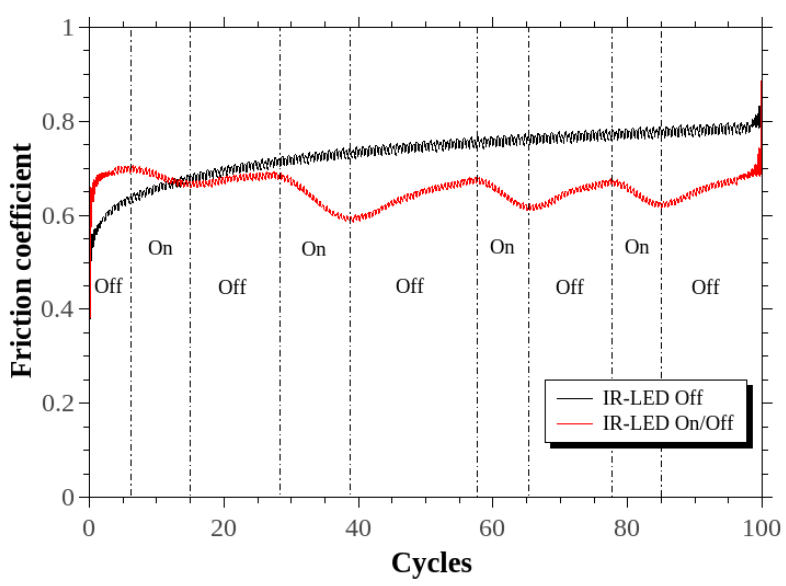

Fig. 17 Tribological behaviour of IR-LED rubbing on NP-PW 2 (Ball: LED $\varnothing 2.76 \mathrm{~mm}-\mathrm{v}: 1 \mathrm{~mm} . \mathrm{s}^{-1}-\mathrm{d}: \pm 0.5 \mathrm{~mm}-\mathrm{F}_{\mathrm{n}}: 20$ $\mathrm{mN}-100$ cycles). Plots are smoothed with a 100 points adjacent averaging algorithm

power emitted by the IR-LED is the one concentrated within a projected area that is the very Hertzian contact area. Thus, by combining elastic contact mechanics [69] and application notes of IR-LED manufacturers [70], the solid angle can be computed by the relationship proposed by Barna [70], that is:

$S_{r}=\frac{A}{R^{2}}$

with $A$, the projected area corresponding here to the Hertzian contact area $-i e, 314.10^{-12} \mathrm{~m}^{2}$ for $\mathrm{F}_{\mathrm{n}}=20 \mathrm{mN}$, and $R$ the radius of the LED cap.

A computed solid angle of about $35.10^{-6}$ steradian finally leads to a thermal power that is emitted within the contact area of about $30 \mu \mathrm{W}$. However, in our concerned wavelength range - ie, $940 \mathrm{~nm}$ - only $68 \%$ of this IR emission is able to be absorbed by the silicon wafer according to the Beer-Lambert law [71], which limits the injected thermal power at $20 \mu \mathrm{W}$ at the most.

As mentioned above, this value can however be reduced or modulated during the tribological test by means of pulse-width modulation using a suitable duty-cycle. In order to set the latter which limits the degradation of the SAM, we need to make the connection between the real injected thermal energy and the contact temperature as reported in Fig. 16. Supposing a tribological test in on-mode of about 10 cycles - ie, corresponding to a duration of $20 \mathrm{~s}$ - the injected energy is around $4.10^{-4} \mathrm{~J}$, which is very close to the damaging threshold (red arrow at $4.5 \cdot 10^{-4} \mathrm{~J}$ ). Hence, a duty-cycle of $50 \%$ is chosen for the sake of safety leading to an average injected thermal power of $10 \mu \mathrm{W}$ which corresponds to a ultimate tribological test duration of 45 s or 22 cycles.

\subsubsection{IR-controlled tribological test}

Figure 17 displays the evolution of the friction coefficient carried out on NP-PW 2 with a duty-cycle of $50 \%-i e$, with a thermal injected power of $10 \mu \mathrm{W}$.

- (i) when the IR-LED is set-off (black curve), the friction coefficient is quite high since the LED's cap is made of silicone. The assessed values are clearly in the range of what it was reported, at room temperature, by many authors, for tribological testings of PDMS on various materials [72,73];

- (ii) when the IR-LED is alternatively set-on and off (red curve), the friction coefficient instantaneously drops when the LED is on ; the decrease clearly depends on the lighting time and so the thermal energy that is injected by the LED within the contact area. This value is easily computed by multiplying the injected power - ie, $10 \mu \mathrm{W}$ - by the on-time $10 \mathrm{~s}$ or 20 s for 5 and 10 cycles, respectively. These values correspond to the blue and black arrows of the Fig. 16 showing the expected contact temperatures of the OTS SAM. Thus the friction coefficient can quickly drop of 12 and $21 \%$ by quickly increasing contact temperature of $25^{\circ} \mathrm{C}$ and $55^{\circ} \mathrm{C}$, respectively. The drop velocity is completely controlled by the duty cycle value. The higher the duty cycle the faster the friction is controlled. It is worth noting that each friction coefficient drop can definitively be attributed only to the IR emission and not to any thermal expansion of the cantilever. Indeed, a flat thermocouple has been mounted on it in order to check any thermal dilatation of the cantilever which could distort the friction force assessment. As a result, the cantilever's temperature stays at the room temperature during the on modes mainly because the pulse-width modulation limits the cantilever's self-heating.

- (iii) as soon as the IR-LED is set-off, the friction coefficient instantly rises showing that a thermal emission source could be a suited way for easily controlling the frictional behaviour - by limiting inertial effects - of nano-patterns in MEMS devices. UV and Laser beams both seem to be good candidates for this purpose $[11,12,13]$;

\section{Conclusion}

Triboactive OTS periodic nano-patterns have been grafted on $\mathrm{Si}(100)$ by using micro-contact printing. It appears that the frictional behaviour of these nano-patterned monolayers can be accurately controlled : (i) at the nanoscale by changing the pattern's period via the pattern's width PW and (ii) at the macroscale by varying the sample temperature. The pattern's width is the key parameter to accurately adjust the friction coefficient of these triboactive surfaces at the macroscale. It has to be adjusted to develop a suitable load bearing capacity. The best value is observed when molecules entanglement between two patterns is completely avoided. By doing this, the thermalinduced tribological behaviour is mainly due to reversible changes in the stiffness of the patterned monolayer leading to modifications of the dissipation mechanisms by involving changes of the van der Waals interchain attraction. Any inertia connected to thermal effect can be reduced using radiative thermal flow instead of conductive one. In that case, friction drops of nanopatterns are completely controlled by the thermal emitted power. In a future paper, the consequence of the patterning on the lifespan and wear of OTS SAMs will be studied. 


\section{References}

1. Lobo R F M, Nanophysics for Energy Efficiency, Springer Briefs in Energy, Springer Cham Heidelberg New York Dordrecht London, (2015). ISBN 978-3-319-17006-0

2. Wang Z L, Lin L, Niu J C S, Zi Y, Triboelectric Nanogenerators, Springer International Publishing Switzerland (2016), ISBN 978-3-319-40038-9

3. Zhang X, Overview of Triboelectric Nanogenerators, in Han M, Zhang X. Zhang H (Eds), Flexible and Stretchable Triboelectric Nanogenerator Devices, 2019 Wiley-VCH

4. Stempflé P, Besnard A, Martin N, Domatti A, Takadoum J, Accurate control of friction with nanosculptured thin coatings: Application to gripping in microscale assembly, Tribology Int, 59:67-78, (2013)

5. Chaillet N, Regnier S, Microrobotics for micromanipulation, ISTE Ltd John Wiley \& Sons Inc, (2010)

6. Gauthier M, Regnier S, Rougeot P, Chaillet N, Analysis of forces for micromanipulations in dry and liquid media, J. of Micromechatronics, 3-4 :389-413, (2006)

7. Rakotondrabe M, Addab Y, Lutz P, Modeling and Control of Stick-slip Micropositioning Devices in Micro, Nanosystems and Systems on Chips, A.Voda (Ed), ISTE Ltd and John Wiley \& Sons, Inc. (2010), ISBN 978-1-84821-190-2

8. Braiman Y, Barhen J, Protopopescu V, Control of Friction at the Nanoscale, Physical Review Letters 90(9):094301, April 2003, (2003)

9. Stempflé P, Domatti A, Dang H-A, Takadoum J, Multiasperity Nanotribology of Self-Assembled Monolayers Grafted on Silicon Wafers Displaying Various Crystallographic Orientations and Nanostructures, Tribology Int, 82:358-374, (2015)

10. Greiner C, Felts J R, Dai Z, King W P, Carpick R W, Controlling Nanoscale Friction through the Competition between Capillary Adsorption and Thermally Activated Sliding, ACS NANO, 6(5):4305-4313, (2012)

11. Sasaki M, Xu Y, Goto M, Control of friction force by light observed by friction force microscopy in a vacuum, Applied Physics Express, 10:015201, (2017)

12. Hendrikx M, Schenning A P H J, Debije M G, Broer D J, Light-triggered formation of surface topographies in azo polymers. Crystals, 7(8), 1-20. [231]. https://doi.org/10.3390/cryst7080231

13. Nanni G, Ceseracciu L, Oropesa-Nunez R, Canale C, Salvatore P, Fragouli D, Athanassiou A, Tunable Friction Behavior of Photochromic Fibrillar Surfaces, Langmuir, 31(22):6072-6077, (2015)

14. Karuppiah K S K, Zhou Y, Woo L K, Sundararajan S, Nanoscale Friction Switches: Friction Modulation of MonomolecularAssemblies Using External Electric Fields, Langmuir, 25(20):12114-12119, (2009)

15. Burgo T A L, Silva C A, Balestrin L B S, Galembeck F, Friction coefficient dependence on electrostatic tribocharging, Scientific Reports, 3(2384), (2013)

16. de Beer S, Switchable Friction Using Contacts of StimulusResponsive and Nonresponding Swollen Polymer Brushes, Langmuir 30, 8085-8090 (2014)

17. Han J, Sun J, Xu S, Song D, Han Y, Zhu H, Fang L, Tuning the Friction of Silicon Surfaces Using Nanopatterns at the Nanoscale , Coatings 2018, 8(1),7, doi:10.3390/coatings8010007

18. Srinivasan $U$, Houston $M R$, Howe $R \mathrm{~T}$, Maboudian $\mathrm{R}$, Alkylsiloxane-based self-assembled monolayers for stiction reduction in silicon micromachines, J. Microelectromech. Syst, $7(2): 252-260,(1998)$

19. Cha K-H, Kim D E, Investigation of the tribological behavior of octadecyltrichlorosilane deposited on silicon, Wear, 251:1169-1176, (2001)

20. Sung I-H, Yang J-C, Kim D-E, Shin B-S, Micro/nanotribological characteristics of self-assembled monolayer and its application in nano-structure fabrication, Wear 255:808-818, (2003)

21. Ren S, Yang S, Zhao Y, Zhou J, Xu T, Liu W, Friction and wear studies of octadecyltrichlorosilane SAM on silicon, Tribology Letters, 13(4) :233, (2002)
22. Bhushan B, Kasai T, Kulik G, Barbieri L, Hoffmann P, AFM study of perfluoroalkylsilane and alkylsilane selfassembled monolayers for antistiction in MEMS/NEMS, Ultramicroscopy, 105:176-188, (2005)

23. Barriga J, Coto B, Fernandez B, Molecular dynamics study of optimal packing structure of OTS self-assembled monolayers on SiO2 surfaces, Tribology Int, 40:960-966, (2007)

24. Lio, A. Charych, D.H., Salmeron, M., Comparative Atomic Force Microscopy Study of the Chain Length Dependence of Frictional Properties of Alkanethiols on Gold and Alkylsilanes on Mica, J. Phys. Chem. B. (1997), 101, 3800-3805

25. Masuko M, Miyamoto H, Suzuki A, Tribological characteristics of self-assembled monolayer with siloxane bonding to $\mathrm{Si}$ surface, Tribology Int, 40:1587-1596, (2007)

26. Booth B D, Martin N J, Buehler E A, McCabe C, Jennings G K, Tribological characterization of gradient monolayer films from trichlorosilanes on silicon, Colloids and Surfaces A: Physicochem. Eng. Aspects, (2012), 412, 57-63

27. Domatti A, Stempflé P, Carrière P, Takadoum J, Multiasperity Nanotribology of Self-Assembled Monolayers Grafted on Silicon Wafers Displaying Various Crystallographic Orientations and Nanostructures, Tribology Letters, 51:207-218, (2013)

28. Stoyanov P, Chromik R R, Materials, Scaling Effects on Materials Tribology: From Macro to Micro Scale, 10 (550):1-47, (2017)

29. Wahl K J, Macroscale to Microscale Tribology-Bridging the Gap, in Y-W. Chung (Eds), Micro-Nanoscale Phenomena in Tribology, 5-21. CRC Press, (2012),ISBN 978-1-4398-3922-5

30. Fadeev A Y, McCarthy T J, Self-Assembly Is Not the Only Reaction Possible between Alkyltrichlorosilanes and Surfaces: Monomolecular and Oligomeric Covalently Attached Layers of Dichloro- and Trichloroalkylsilanes on Silicon, Langmuir, 16(18):7268-7274, (2000)

31. Naik V V, Crobu M, Venkataraman N V, Spencer N D, Multiple Transmission-Reflection IR Spectroscopy Shows that Surface Hydroxyls Play Only a Minor Role in Alkylsilane Monolayer Formation on Silica, J. Phys. Chem. Lett, 4:2745-2751, (2013)

32. Gardos M N, Tribological behaviour of polycrystalline and single-crystal silicon, Tribology Letters, 2:355-373, (1996)

33. Quist A P, Pavlovic E, Oscarsson S, Recent advances in microcontact printing, Analytical and Bioanalytical Chemistry, 381(3):591-600, (2005)

34. Kang S, micro/nano replication processes and applications, John Wiley \& Sons, Inc., Hoboken, New Jersey., (2012)

35. Qin D, Xia Y, Whitesides G M, Soft lithography for micro- and nanoscale patterning, Nature protocols, 5(3):491-502, (2010)

36. Bennès $\mathrm{J}$, Ballandras $\mathrm{S}$, Chérioux $\mathrm{F}$, Easy and versatile functionalization of lithium niobate wafers by hydrophobic trichlorosilanes, Applied Surface Science, 255:1796-1800, (2008)

37. Perl A., Reinhoudt D N, Huskens J, Microcontact Printing: Limitations and Achievements, Advanced Materials, 21(22):2257-2268, (2009)

38. Arslan G, Özmen M, Hatay I, Gübbük I H, Ersöz M, Microcontact Printing of an Alkylsilane Monolayer on the Surface of Glass, Turkish Journal of Chemistry, 32 :313-321, (2008), 32:313-321

39. Lipomi D J, Martinez R V, Cademartiri L, Whitesides G M, Soft Lithographic Approaches to Nanofabrication, in Polymer Science: A Comprehensive Reference, Vol. 7, pages 211-231, (2012)

40. Whitesides G M, Love J C, The art of building small, Scientific American Reports, 17(3):13-21, September 2007

41. Belgardt C, Sowade E, Blaudeck T, Baumgärtel T, Graaf H, von Borczyskowski C, Baumann $\mathrm{R}$ R, Inkjet printing as a tool for the patterned deposition of octadecylsiloxane monolayers on silicon oxide surfaces, Phys. Chem. Chem. Phys., 15 (20):7494-7504, (2013)

42. Johnston I D, McCluskey D K, Tan C K L, Tracey M C, J. Mechanical characterization of bulk Sylgard 184 for microfluidics and microengineering, Micromech. Microeng., 24:035017, (2014)

43. Launer P.J., Arkles B., Infrared analysis of organosilicon compunds: spectra-structure correlations, Reprinted from Silicon 
Compounds: Silanes \& Silicones, 2013 Gelest, Inc Morrisville, PA, www.gelest.com, 215-547-1015,

44. Subrahmanyam A, Suresh Kumar C, Kelvin Probe for Surface Engineering. Ane Books Pvt. Ltd, (2009), ISBN 978-81-9084063-7

45. Ermakov S, Beletskii A, Eismont O, Nikolaev V, Liquid Crystals in Biotribology Springer Cham Heidelberg New York Dordrecht London, (2016)

46. Szwajca A, Wei J, Schukfeh M I, Tornow M, Self-assembled monolayers of alkyl-thiols on InAs: A Kelvin probe force microscopy study, Surface Science, 633:53-59, (2015)

47. Rossi F, Contact potential measurement: Spacing-dependence errors., Review of Scientific Instruments, (1992), 63 (9): p. 4174-4181

48. di Natale C, Goletti C, Paolesse R, Drago M, Macagnano A, Mantini A, Troitsky V I, Berzina T S, Cocco M, D'Amico A, Kelvin probe investigation of the thickness effects in Langmuir-Blodgett films of pyrrolic macrocycles sensitive to volatile compounds in gas phase, Sensors and Actuators B, (1999) 57 Issues 1-3: p. 183-187

49. Alloway M, Hofmann M, Smith D L, Gruhn N E, Graham A L, Colorado R, Wysocki V H, Lee T R, Lee P A, Armstrong N R, Interface Dipoles Arising from Self-Assembled Monolayers on Gold: UV-PhotoemissionStudies of Alkanethiols and Partially Fluorinated Alkanethiols, J. Phys. Chem. B, 107:11690-11699, (2003)

50. Evans S D, Ulman A, Surface potential studies of alkyl-thiol monolayers adsorbed on gold, Chem. Phys. Lett., 170(5,6):462, (1990)

51. Lü J, Delamarche E, Eng L, Bennewitz R, Meyer E, Güntherodt H-J, Kelvin probe force microscopy on surfaces: investigation of the surface potential of self-assembled monolayers on gold, Langmuir, 15:8184-8188, (1999)

52. Heinz H, Vaia R A, Farmer B L, Relation between Packing Density and Thermal Transitions of Alkyl Chains on Layered Silicate and Metal Surfaces, Langmuir, 24:3727-3733, (2008)

53. Ito E, Arai T, Hara M, Noh J, Surface Potential Change Depending on Molecular Orientation of Hexadecanethiol SelfAssembled Monolayers on $\mathrm{Au}(111)$, Bull. Korean Chem. Soc., 30(6):1309-1312, (2009)

54. Kasai T, Fu X Y, Rigney D A, Zharin A L, Applications of a non-contacting Kelvin probe during sliding, Wear, 225229:1186-1204, (1999)

55. Li Y, Li D Y, J. Prediction of elastic-contact friction of transition metals under light loads based on their electron work functions, Phys. D: Appl. Phys., 40:5980-5983, (2007)

56. Stempflé P, Pantalé O, Djilali T, Kouitat Njiwa R, Bourrat $\mathrm{X}$, Takadoum J, Evaluation of the real contact area in threebody dry friction by micro-thermal analysis, Tribology Int, 43:1794-1805, (2010)

57. Chandekar A, Sengupta S K, Whitten J E, Thermal stability of thiol and silane monolayers: A comparative study, Applied Surface Science, 256:2742-2749, (2010)

58. Khatri O P, Biswas S K. Thermal stability of octadecyltrichlorosilane self-assembled on a polycrystalline aluminium surface, Surface Science, 572:228-238,(2004)

59. Kluth G J, Sander M, Sung M M, Maboudian R, Study of the desorption mechanism of alkylsiloxane self-assembled monolayers through isotopic labeling and high resolution electron energy-loss spectroscopy experiments, J. Vac. Sci. Technol. A, 16(3):932-936, (1998)

60. te Riet J, Smit T, Gerritsen J W, Cambi A, Elemans J A A W, Figdor C G, Speller S, Molecular Friction as a Tool to Identify Functionalized Alkanethiols, Langmuir, (2010), 26 (9) 6357-6366

61. Brewer N J, Beake B D, Leggett G J, Friction Force Microscopy of Self-Assembled Monolayers: Influence of Adsorbate Alkyl Chain Length, Terminal Group Chemistry, and Scan Velocity, Langmuir (2001), 17, 6, 1970-1974

62. Szlufarska I, Chandross M, Carpick R W, Recent advances in single-asperity nanotribology, J. Phys. D: Appl. Phys., 41:123001, (2008)

63. Munz M, J. Force calibration in lateral force microscopy: a review of the experimental methods, Phys. D: Appl. Phys., 43:063001, (2010)
64. Meyer E, Lüthi R, Howald L, Bammerlin M, Guggisberg M, Günterodt H J, Scandella L, Gobrecht J, Schumacher A, and Prins R, Friction Force Spectroscopy, in B.N.J. Persson and E. Tosatti (Eds), Physics of Sliding Friction, pages 349-367, (1996)

65. Cappella B, Dietler G, Force-distance curves by atomic force microscopy, Surface Sci. Reports, 34, 1-3,(1999),1-104

66. Stempflé $\mathrm{P}$ and Takadoum J, Multi-asperity nanotribological behavior of single-crystal silicon: Crystallography-induced anisotropy in friction and wear, Tribology Int, 48:35-43, (2012)

67. Stempflé P, Domatti A., Carriere P., Takadoum J., Lifespan Enhancement of Silicon based MEMS using periodic nanopatterned Self-Assembled Monolayers, 7th Eur. Conf. on Tribology - ECOTRIB 2019, 12-14 June 2019, Vienna

68. www.osram-os.com, OSRAM Opto Semi-conductors Technical chart, SFH 4725S (Version 1.7, 2018-10-09)

69. Popov, V.L., HeB, M., Willert, E., Handbook of contact mechanics, Springer, (2019),ISBN 978-3-662-58709-9

70. Barna P., Fundamental of the Infrared Physical Layer, Microchip Application Note AN 243, (2004) Microchip Technology Inc, DS00243A, 1-12

71. Palik, D. Handbook of Optical Constants of Solids, Academic Press, Boston, (1985)

72. Hénot M., Grzelka M, Zhang J, Mariot S, Antoniuk I,Drockenmuller E, Léger L, Restagno F, TemperatureControlled Slip of Polymer Melts on Ideal Substrates, Phys. Rev. Lett. 121, (2018), 177802

73. Penskiy I., Gerratt, A.P., Bergbreiter S., J. Friction, adhesion and wear properties of PDMS films on silicon sidewalls, Micromech. Microeng. 21 (2011) 105013 